\title{
Этиологическая структура
} острых респираторных

\section{вирусных инфекций у Аетей,}

\section{госпитализированных}

\section{в стационар в 2015-2018 гг.}

\author{
Рябиченко Т.И., \\ Скосырева Г.А., \\ Обухова 0.0., \\ Курская О.Г., \\ Косьянова Т.Г., \\ Горбенко О.М., \\ Шваюк А.П.
}

\begin{abstract}
Федеральное государственное бюджетное научное учреждение "Федеральный исслеАовательский центр фундаментальной и трансляционной меАицины", 630117, г. Новосибирск, Российская Федерация
\end{abstract}

Острые респираторные вирусные инфекции (ОРВИ) играют значительную роль в формировании заболеваемости у детей. В то же время исследований, связанных с изучением этиологической структуры ОРВИ, недостаточно. Представлены результаты анализа структуры ОРВИ у детей с тяжелым и среднетяжелым течением заболевания, госпитализированных в детскую клиническую больницу г. Новосибирска в 20152018 гг.

Цель исследования - изучение структуры ОРВИ с определением этиологического агента у детей, госпитализированных в стационар.

Материал и методы. Обследованы 1137 детей в возрасте до 15 лет. Для определения этиологического фактора проведено исследование методом RT-PCR (тест-системы Ампли СенсОРBИ-скрин-FL «ИнтерЛабСервис», Россия) смывов слизи из носа и зева на наличие генетического материала вирусов, вызывающих ОРВИ: вирусы гриппа А и В, парагриппа типов 1-4, респираторно-синцитиальный (RS) вирус, метапневмовирус, 4 типа коронавируса человека, риновирус, аденовирус и бокавирус.

Результаты. Наиболее часто выявляли RS-вирус (23,52\%), вирусы гриппа A и В (19,73\%) и риновирус $(19,21 \%)$. В динамике наблюдения обнаружено нарастание доли микст-инфекций. Отмечена существенная частота комбинированного поражения респираторного и желудочно-кишечного тракта, что значимо для детей раннего и дошкольного возраста.

Заключение. В группе обследованных госпитализированных детей в этиологической структуре ОРВИ первые 3 ранговых места занимали RS-инфекция, грипп и риновирусная инфекция. На долю микстинфекций, обусловленных чаще всего 2 вирусами, приходилось 23,44\% случаев. Диарейный синдром наиболее часто выявлялся в возрастной группе от 1 года до 3 лет, но в целом число детей с диареей не превышало 11,17\%. В группе детей с диарейным синдромом определены норо- и ротавирусы в сочетании с другими респираторными вирусами.

Финансирование. Исследование не имело спонсорской поддержки.

Конфликт интересов. Авторы заявляют об отсутствии конфликта интересов.

Вклад авторов. Концепция и дизайн исследования - Рябиченко Т.И., Скосырева Г.А.; сбор и обработка материала Горбенко О.М., Косьянова Т.Г., Шваюк А.П.; статистическая обработка - Рябиченко Т.И., Обухова Г.А.; лабораторная диагностика - Курская 0.М.; написание текста - Скосырева Г.А., Обухова 0.0.; редактирование - Рябиченко Т.И.

Для цитирования: Рябиченко Т.И., Скосырева Г.А., Обухова 0.0., Курская О.Г., Косьянова Т.Г., Горбенко 0.М., Шваюк А.П. Этиологическая структура острых респираторных вирусных инфекций у детей, госпитализированных в стационар в 20152018 гг. // Инфекционные болезни: новости, мнения, обучение. 2021. T. 10, № 2. С. 47-53. D0I: https://doi.org/10.33029/23053496-2021-10-2-47-53

Статья поступила в редакцию 13.01.2021. Принята в печать 31.03.2021.
Ключевые слова: дети, респираторнье инфекции, диарейный синдром 
Etiological structure of acute respiratory viral infections in children hospitalized in 2015-2018

Ryabichenko T.I., Skosyreva G.A., Obukhova 0.0., Kurskaya O.G., Kosyanova T.G., Gorbenko O.M.,

Shvayuk A.P.
Federal Research Center of Fundamental and Translational Medicine, 630117, Novosibirsk, Russian Federation

Acute respiratory viral infections (ARVI) play an important role in morbidity formation among children. At the same time, studies about the ARVI etiological structure are not enough. The article presents the results of structure analyses of ARVI in children with severe and moderate degrees of disease hospitalized in the children's clinical hospital of Novosibirsk for the period 2015-2018.

This research aimed to analyze the morbidity of acute respiratory viral infections with the estimation of a causal virus in children admitted to the hospital for the period 2015-2018.

Material and methods. In this study, 1137 children aged between 0 and 15 years were examined. In order to determine the etiological factor in children with damage of the upper or lower respiratory tract, by using the method of RT-PCR (AmpliSensARVI-screen-FL test systems (InterLabService, Russia), mucus from the nose and throat was examined for the presence of genetic material of viruses that cause ARVI (influenza A and B viruses, parainfluenza viruses of types 1-4, respiratory syncytial virus, metapneumovirus, four types of human coronavirus, rhinovirus, adenovirus, and bocavirus).

Results. The research found that the most frequently detected pathogens are respiratory syncytial virus (23.52\%), influenza A and B viruses (19.73\%) and rhinovirus (19.21\%). Observe the dynamics some fluctuations in the detection of mentioned viral agents and increasing of mixed infections were detected. In addition, the importance of respiratory and gastrointestinal tract combined lesions, particularly for infants and preschool age children has been noted.

Conclusion. The distribution of respiratory viruses in children with severe ARVI who required hospitalization was assessed. It was shown the significance of the respiratory syncytial infection virus, influenza virus and rhinovirus in the etiological structure of hospitalized children of different ages that damage not only the respiratory tract, but also to the gastrointestinal tract. This is an important factor in optimizing the diagnosis, treatment and prevention of viral infections in children.

Funding. The study was not sponsored.

Conflict of interest. The authors declare that there is not conflict of interest.

Contribution. Concept and design of the study - Ryabichenko T.I., Skosyreva G.A.; collection and processing of the material Gorbenko 0.M., Kosyanova T.G., Shvayuk A.P.; statistical processing - Ryabichenko T.I., Obukhova G.A.; laboratory diagnostics Kurskaya 0.M., writing of the text - Skosyreva G.A., Obukhova 0.0.; editing - Ryabichenko T.I.

For citation: Ryabichenko T.I., Skosyreva G.A., Obukhova 0.0., Kurskaya 0.G., Kosyanova T.G., Gorbenko 0.M., Shvayuk A.P. Etiological structure of acute respiratory viral infections in children hospitalized in 2015-2018. Infektsionnye bolezni: novosti, mneniya, obuchenie [Infectious Diseases: News, Opinions, Training]. 2021; 10 (2): 47-53. DOI: https://doi.org/10.33029/2305-3496-202110-2-47-53 (in Russian)

Received 13.01.2021. Accepted 31.03.2021.

$\Pi$ роблемы распространенности острых респираторных вирусных инфекций (ОРВИ), особенностей их течения, развития осложнений, а следовательно, подходов к терапии, несмотря на длительную историю вирусологических, клинических и патогенетических исследований, остаются крайне актуальными. ОРВИ - большая и разнообразная группа заболеваний, объединяемых вирусной природой возбудителя, общим механизмом передачи и клинической картиной поражения верхних и, реже, нижних отделов респираторного тракта $[1,2]$. Наиболее высокие показатели заболеваемости ОРВИ регистрируют в детском возрасте. Это связано с особенностями формирования иммунного реагирования у детей: низкий по сравнению со взрослыми уровень сывороточного и секреторного IgA, критические периоды становления иммунной системы, нарушение микроэкологического состояния как кишечника, так и носоглотки [3]. Также значимыми являются экзогенные факторы, такие как нерациональные питание и режим дня, высокий риск инфицирования, пассивное курение, полипрагмазия, в том числе назначение антибактериальных препаратов без показаний [4]. Проблема ОРВИ определяется также их широким распространением, полиэтиологичностью (согласно данным литературы, общее число серотипов респираторных вирусов превышает 300). Большое количество респираторных вирусов вызывает целый спектр заболеваний, от легких самоограниченных симптомов при вовлечении в процесс верхних дыхательных путей (ринит) до угрожающих жизни синдромов, связанных с поражением нижних дыхательных путей, таких как бронхиолит и пневмония [5]. Внедрение ПЦР-диагностики не только повысило показатели выявления уже известных вирусов, но и привело к обнаружению ранее неизвестных вирусов, поражающих 
дыхательные пути. Идентифицированы метапневмовирус человека (HMPV) и бокавирус человека (HBoV) $[6,7]$. 0coбенностью респираторных вирусов является их способность к антигенным изменениям, что позволяет им ускользать от врожденного и приобретенного противовирусного иммунитета, вызванного предыдущей инфекцией и/или вакцинацией. Незначительные изменения в структуре поверхностных антигенов происходят в результате точечных мутаций в генах, которые их кодируют [8]. Такая форма антигенной изменчивости (антигенный дрейф), как и другая - антигенный шифт (полная замена гена, которая приводит к появлению нового антигенного варианта вируса), делают невозможным формирование долговременной иммунологической памяти, что и обусловливает повторное инфицирование и заболевание, а также крайне затрудняет проведение специфической профилактики [9].

Для различных возбудителей ОРВИ характерна определенная сезонность $[10,11]$, но, безусловно, наиболее высокая заболеваемость острыми респираторными инфекциями в Сибири отмечается в осенне-зимний и весенний периоды. Клиническая диагностика респираторных вирусных инфекций затруднена, поскольку при различных вирусных инфекциях достаточно часто развивается однотипная симптоматика, и, наоборот, при заболеваниях, вызванных однородным этиологическим агентом, клинические проявления могут быть различными $[12,13]$. Это требует более активного исследования иммунологических реакций при различных ОРВИ с определением их клинико-иммунологических особенностей с целью возможного прогнозирования тяжести течения заболевания и назначения оптимальной терапии [14].

Обычно при ОРВИ поражаются верхние и нижние дыхательные пути. В то же время все чаще при острых вирусных инфекциях у детей исследователи стали обращать внимание на достаточно высокую частоту поражения желудочнокишечного тракта (ЖКТ) $[15,16]$. На долю вирусных диарей приходится до 80\% всех случаев острых кишечных инфекций у детей [17]. Диспептический синдром возникает при вирусных диареях, он обусловлен поражением различных отделов кишечника и клинически проявляется в виде энтерита или гастроэнтерита. Существуют данные, свидетельствующие о том, что при изолированном диарейном синдроме чаще всего преобладают ротавирусная и норовирусная инфекции, при этом гастроэнтериты вирусной этиологии превалируют у детей до 6 лет $[18,19]$. Однако ряд авторов считают, что вирусные диареи вызывают также такие инфекционные агенты, как аденовирусы, коронавирусы, саповирусы и др., для которых ранее основной мишенью считался респираторный тракт [20]. Актуальность исследования клинико-иммунологических особенностей вирусных процессов, сопровождающихся диареей, связана с дисфункцией микробиоценоза кишечника, что может обусловливать более тяжелое течение острого периода вирусного заболевания и затяжное течение восстановительных реакций $[6,15,17,19]$.

Согласно наблюдениям некоторых авторов, за последние годы удельный вес детей с инфекциями, обусловленными более чем 1 вирусным агентом, возрос и достигает 11,8\% [5]. Отмечено, что чаще всего у детей микст-инфекция была

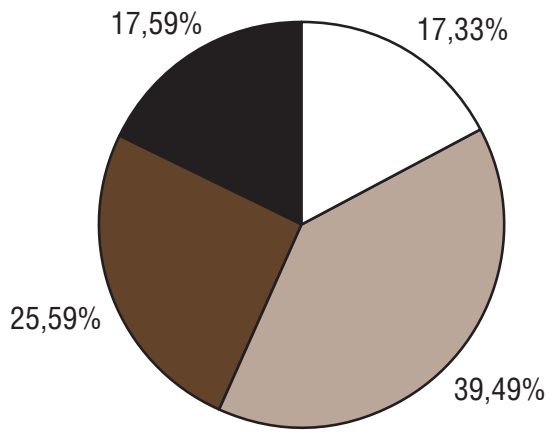
$\square$ До 1 года
$\square$ 1-3 года
4-7 лет
8-14 лет

Рис. 1. Возрастная структура Аетей с острыми респираторными вирусными инфекциями, госпитализированных в стационар в 2015-2018 гг.

вызвана 2 вирусами [5]. 0 характере течения смешанной вирусной инфекции существуют противоречивые данные, характеризующие совместное действие 2 вирусов как утяжеляющий фактор [21].

Цель исследования - изучение структуры ОРВИ с определением этиологического агента у детей, госпитализированных в стационар.

\section{Материал и методы}

На базе ГБУз НСО ДГКБ № 6 (Новосибирск) в 2015-2018 гг. обследованы 1137 детей в возрасте до 15 лет, госпитализированных с диагнозом ОРВИ.

Для определения этиологического агента у детей с ОРВИ исследовали биологические образцы (смывы слизи из носа и зева) на наличие генетического материала вирусов, вызывающих острые респираторные заболевания (РНК респира-

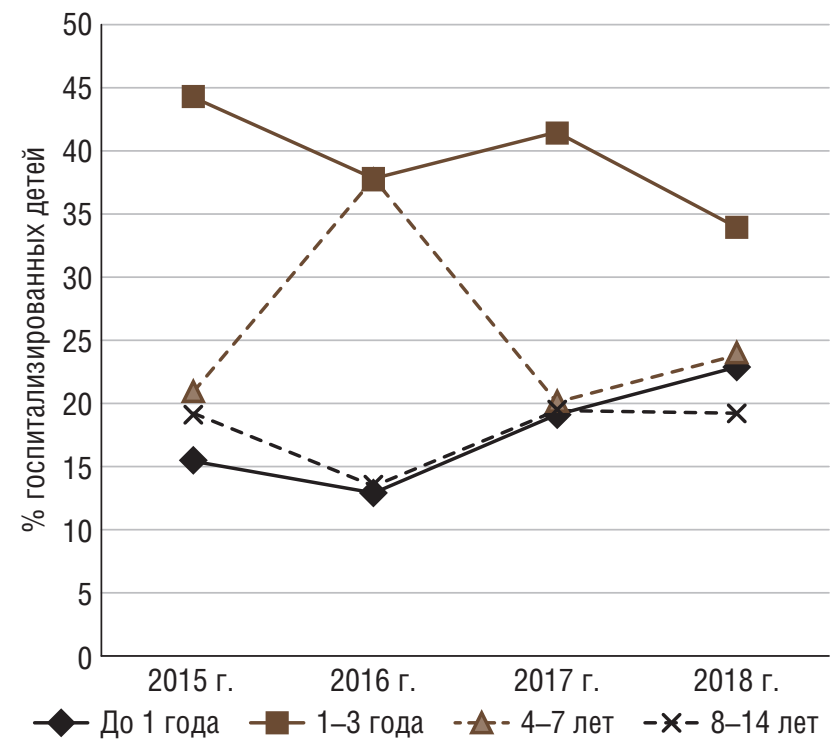

Рис. 2. Особенности динамики числа госпитализированных Аетей с острыми респираторными вирусными инфекциями в разных возрастных группах в 2015-2018 гг. 


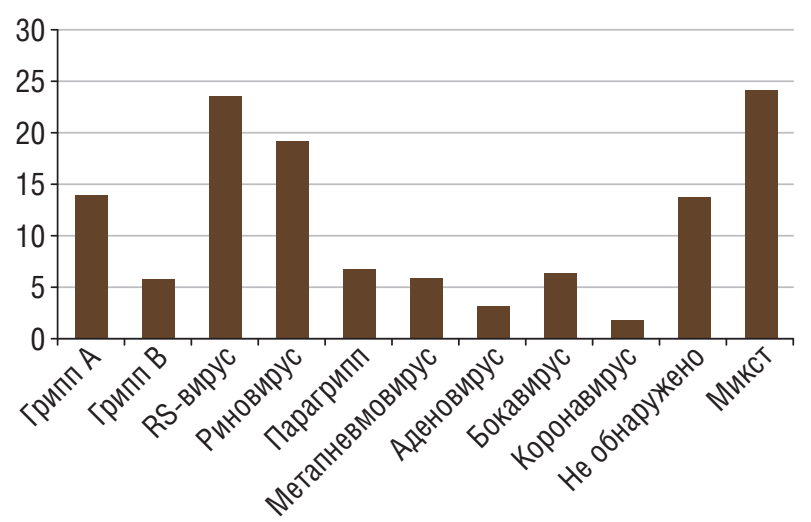

Рис. 3. Этиологическая структура острых вирусных инфекций у Аетей Новосибирска. госпитализированных в 20152018 гг. (в \% от общего числа Аетей)

торно-синцитиального (RS) вируса, метапневмовируса, вирусов парагриппа 1, 2, 3 и 4-го типов, коронавирусов видов 0C43, E229, NL63 и HKUI, риновирусов, ДНК аденовирусов групп В, С, Е и бокавируса) методом ПЦР с гибридизационно-флюоресцентной детекцией продуктов амплификации в режиме реального времени на оборудовании Real-time CFX96 (Bio-Rad, США) с помощью тест-систем «Ампли Сенс OРВИ-скрин-FL» («ИнтерЛабСервис», Россия).

У детей с диарейным синдромом дополнительно определяли антиген ротавируса и норовируса человека в пробах фекалий с помощью коммерческих тест-систем «Ротавирусантиген-ИФА-БЕСТ» и «Норовирус-антиген-ИФА-БЕСТ» производства компании «Вектор Бест» (Новосибирск, Россия) иммуноферментным методом по инструкции производителя (качественный метод). В ходе статистической обработки рассчитаны экстенсивные показатели.

\section{Результаты и обсужкение}

Анализ полученных материалов показал, что наиболее часто госпитализировали в стационар детей с ОРВИ в возрасте от 1 года до 7 лет (65,08\%), - возможно, это было связано с более тяжелым течением болезни или наличием осложнений. Повышение числа случаев заболеваний ОРВИ в возрасте от 1 года до 3 лет и от 4 до 7 лет, по всей видимости, обусловлен, помимо критического периода созревания иммунной системы (4-6 лет), еще и началом посещения детьми образовательных учреждений - дошкольных (3 года) и школы (7 лет).

Возрастная структура детей с ОРВИ, госпитализированных в 2015-2018 гг. представлена на рис. 1.

Среди обследованных детей доля мальчиков составила 47\%, девочек - 53\%. Следует отметить, что в группе до

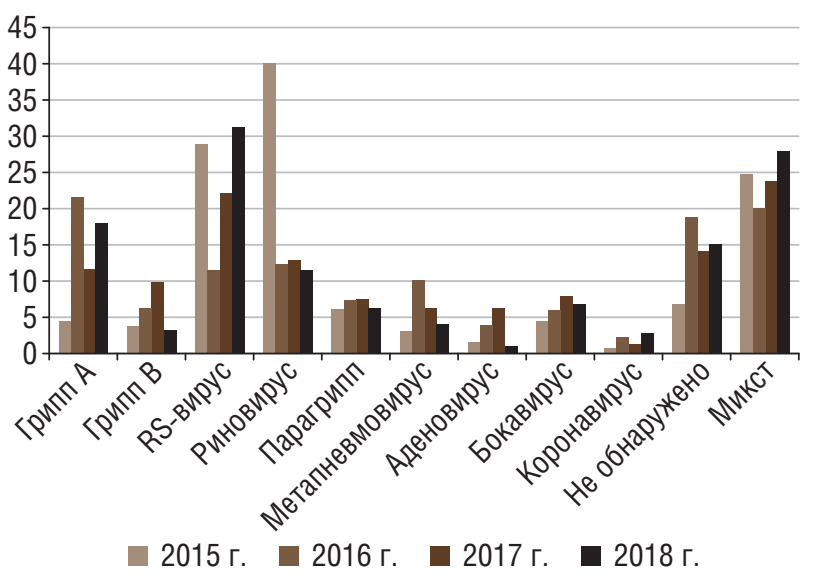

Рис. 4. Этиологическая структура острых вирусных инфекций у госпитализированных детей Новосибирска по годам наблюАения

1 года и в подростковом возрасте число госпитализированных с ОРВИ было сопоставимо: 117 (17,33\%) и 200 (17,59\%) детей соответственно. Возможно, это обусловлено сохранением грудного вскармливания в группе детей до 1 года, что предотвращает тяжелое течение ОРВИ или развитие осложнений заболевания. В подростковом возрасте, как правило, организм уже достигает количественных показателей взрослого, а также формируются зрелые функциональные возможности иммунной системы, что обеспечивает нетяжелое течение инфекционного процесса вирусных инфекций.

В то же время в динамике наблюдения в разных возрастных группах наблюдается изменение числа случаев ОРВИ, потребовавших госпитализации (рис. 2).

Независимо от года исследования, чаще всего госпитализировали детей от 1 года до 3 лет. При этом наибольшая доля заболевших в группе приходилась на 2015 г., в последующие годы наблюдали некоторое снижение числа госпитализированных. В возрастной группе 4-7 лет максимальный удельный вес заболевших отмечен в 2016 г. и был близок к показателю возрастной группы 1-3 года, затем имел место резкий спад в 2017 г. и некоторое повышение в 2018 г. В группах до 1 года и 8-14 лет значения показателей были близки с некоторым повышением в 2016-2018 гг.

Возможно, изменение числа детей, госпитализированных с ОРВИ, было обусловлено особенностями этиологической структуры вирусных инфекций. В связи с этим проанализирована частота встречаемости различных вирусов как причинно-значимых агентов у детей с тяжелым или осложненным течением ОРВИ в динамике наблюдения по годам (рис. 3).

Из данных рис. 3 следует, что наиболее часто в качестве этиологического агента ОРВИ определяли RS-вирус (25,04\%), риновирус (12,16\%), а также вирус гриппа A (17,14\%).

Частота Аиарейного синдрома в группах обследованных детей

\begin{tabular}{|c|c|c|c|c|} 
Кииническое проявление & \multicolumn{4}{|c|}{ Возрастная группа, годы } \\
\cline { 2 - 5 } & $<1$ & $\mathbf{1 - 3}$ & $\mathbf{4 - 7}$ & $\mathbf{8 - 1 5}$ \\
\hline Аиарейный синаром, абс. (\%) & $21(16,54)$ & $53(41,73)$ & $31(24,41)$ & $22(17,32)$ \\
\hline
\end{tabular}


У 14,9\% детей генетического материала определяемых вирусов не обнаружено, однако это не исключает отсутствие вируса как этиологического фактора. В то же время в 23,44\% случаев была выявлена микст-инфекция. В этой группе больных определяли, как правило, разнообразное сочетание 2 вирусов: риновирус + бокавирус, риновирус + парагрипп, грипп A + RS, грипп + риновирус, грипп B + RS, грипп B + бокавирус, грипп B + метапневмовирус и др.

В ходе анализа установлена частота выявления генетического материала различных вирусов в разные годы наблюдения (рис. 4).

Отмечено снижение числа выявления RS-вируса в 2016 г., рост доли риновируса в 2015 г., более низкое значение выявления вируса гриппа А в 2015 г. и гриппа В в 2017 г., нарастание метапневмовирусной инфекции в 2015 г. по сравнению с другими годами наблюдения.

При этом тенденции, определенные для общей группы детей, в целом сохранялись. Выявлено достаточно высокое число детей с неуточненной этиологией ОРВИ, микстинфекцией на протяжении всего периода наблюдения.

Клинически у 127 (11,17\%) детей с признаками поражения респираторного тракта при поступлении в стационар отмечено наличие диарейного синдрома разной степени выраженности без развития эксикоза (см. таблицу).

Следует отметить, что рота- или норовирус при диарее идентифицирован у 102 (8,97\%) детей, но не изолированно, а в сочетании с другими вирусами респираторной группы. Наиболее часто выявляли рота- и норовирус в группах детей до 1 года и от 1 года до 3 лет. Вирусы гриппа A, RS-вирусы, вирус парагриппа чаще определяли при сочетанном поражении респираторного тракта и ЖКТ (рис. 5).

В целом в 10,24\% случаев установлено сочетание вирусных агентов, а в 9,89\% случаев генетический материал определяемых вирусов не обнаружен.

\section{Зак^ючение}

Таким образом, можно констатировать, что достаточно тяжелое течение ОРВИ, при котором требуется госпитализация, наиболее часто наблюдается в возрастных группах 1-3 года и 4-7 лет, т.е. в период от 1 года до 7 лет. Кроме того, следует отметить, что тяжелое течение ОРВИ может быть обу-

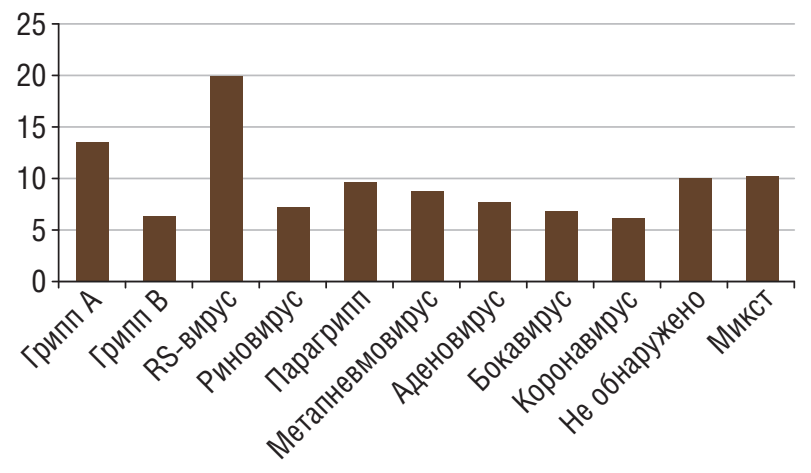

Рис. 5. Этиологическая структура респираторных вирусов у Аетей с диарейным синдромом

словлено различными видами вирусов или их комбинацией. В группе обследованных детей в этиологической структуре ОРВИ первые 3 ранговых места занимали RS-инфекция, грипп и риновирусная инфекция. На долю микст-инфекций, обусловленных чаще всего 2 вирусами, приходилось 23,44\% случаев. Генетический материал вирусов парагриппа, аденовирусов, метапневмовирусов, бокавирусов, коронавирусов обнаружен у 23,85\% обследованных детей. Отмечена тенденция к увеличению числа детей с микст-инфекцией, обусловленной сочетанием 2 вирусных агентов и более. В то же время отсутствие генетического материала вирусов как причинных факторов ОРВИ не может расцениваться как отсутствие вирусной инфекции.

Диарейный синдром наиболее часто выявляли в возрастной группе от 1 года до 3 лет, но в целом число детей с диареей не превышало $11,17 \%$. В группе детей с диарейным синдромом определены норо- и ротавирусы в сочетании с другими респираторными вирусами. Диарейный синдром в сочетании с респираторным утяжеляет течение инфекционного процесса ввиду дополнительного поражения ЖКТ, проявляющегося клинически. По всей видимости, это связано с нарушением микробиоты кишечника. Изменение микробиоты требует не только более длительной реабилитации, но и может провоцировать развитие местных и системных иммунных, метаболических и других нарушений, оказывающих значимое влияние на качество жизни детей.

\section{CBEAEHИЯ ОБ АВТОРАХ}

ФИЦ ФТМ, Новосибирск, Российская Федерация:

Рябиченко Татьяна Ивановна (Tatiana I. Ryabichenko) - доктор медицинских наук, ведущий научный сотрудник лаборатории иммунологии

E-mail:2925871@mail.ru

https://orcid.org/0000-0002-0990-0078

Скосырева Галина Александровна (Galina A. Skosyreva) - доктор медицинских наук, старший научный сотрудник лаборатории иммунологии

E-mail: skosyreva43@mail.ru

https://orcid.org/0000-0001-5477-3445

Обухова Ольга Олеговна (Olga 0. Obukhova) - доктор медицинских наук, заведующий лабораторией иммунологии E-mail: trio188@yandex.ru

https://orcid.org/0000-0002-9834-1799 
Курская Ольга Григорьевна (Olga G. Kurskaya) - кандидат медицинских наук, старший научный сотрудник лаборатории вирусологии

E-mail: kurskaya09_@mail.ru

https://orcid.org/0000-0002-1931-2026

Косьянова Тамара Геннадьевна (Tamara G. Kosyanova) - старший лаборант лаборатории иммунологии

E-mail: kosyanova59@inbox.ru

https://orcid.org/0000-0002-3176-6960

Горбенко Ольга Михайловна (Olga M. Gorbenko) - кандидат медицинских наук, старший научный сотрудник лаборатории иммунологии

E-mail: gorbenko.olga.m@bk.ru

https://orcid.org/0000-0002-5672-9234

Шваюк Аля Петровна (Alya P. Shvayuk) - кандидат медицинских наук, старший научный сотрудник лаборатории иммунологии E-mail: alya.shvayuk@bk.ru

https://orcid.org/0000-0002-8247-7085

\section{ヘИТЕРАТУРА}

1. Рубис ^.В. Характеристика возбудителей острых респираторных вирусных инфекций и значение Аезинфекционных мероприятий в преАупрежАении их распространения // Аетские инфекции. 2018. Т. 17, № 1. C. 34-40.

2. Chen N. et al. Epidemiological and clinical characteristics of 99 cases of 2019 novel coronavirus pneumonia in Wuhan, China: a descriptive study // Lancet. 2020. Vol. 395, N 10 223. P. 507-513. DOI: https:// doi.org/10.1016/S0140-6736(20)30211-7

3. Каннер Е.В., Максимов М.^, Ермолаева А.С., Горелов А.В. Острые респираторные инфекции у Аетей: особенности иммунного ответа и пути коррекции // РМЖ. Медицинское обозрение. 2018. № 8 (11). С. 74-78.

4. Зайцева С.В. Рациональная терапия острых респираторных заболеваний у летей. // Consilium Medicum. Педиатрия. 2019. № 4 C. 32-38. DOI: https://doi.org/10.26442/26586630.2019.4.190748

5. Гладких Р.А., Молочный В.П. Будакова А.В., Троценко О.Е., Резник В.И., Полеско И.В. Клинико-эпидемиологическая характеристика острых респираторных вирусных инфекций у госпитализированных Аетей г. Хабаровска в эпидемических сезонах 2014-2017 гг. // Аетские инфекции. 2018. Т. 17, № 2. С. 6-14.

6. Cebey-Lopez M., Herberg J., Pardo-Seco J., Gomez-Carballa A., Martinon-Torres N., Salas A. et al. Viral co-infections in pediatric patients hospitalized with lower tract acute respiratory infections // PLoS One. 2015. Vol. 10, N 9. Article ID e0136526. DOI: https://doi.org/10.1371/ journal.pone.0136526 PMID:26332375

7. Allander T., Tammi M.T., Eriksson M., Bjerkner A., Tiveljung-Lindell A., Andersson $\mathrm{B}$. Cloning of a human parvovirus by molecular screening of respiratory tract samples // Proc. Natl Acad. Sci. USA. 2005. Vol. 102, N 36. P. 12 891-12 896.

8. Ludvigsson J.F. Systematic review of COVID-19 in children show milder cases and a better prognosis than adults // Acta Paediatr. 2020. Vol. 109. P. 1088-1095. DOI: https://doi.org/10.1111/apa.15270

9. Малахов А.Б., Ртищев А.Ю., Колосова Н.Г. Грипп и острые респи раторные инфекции у детей: стратегия выбора этиотропной терапии // Практическая пульмонология. 2018. № 2. С. 34-40.

10. Кокорева С.П., Трушкина А.В., Разуваев О.А., Казарцева Н.В. Этиологическая структура острых респираторных заболеваний в 2009 2013 гг. у детей г. Воронежа // Аетские инфекции. 2015. № 4. С. 53-56.
11. Михайлова В.Е., Чудакова Т.К., Ярушкина М.С., Романовская А.В., Хворостухина Н.Ф. Респираторно-синцитиальная вирусная инфекция: клинико-лабораторные особенности // Аетские инфекции. 2017. Т. 16 № 2. C. 23-25.

12. Taylor S., Lopez P., Weckx L., Borja-Tabora C., Ulloa-Gutierrez R. Lazcano-Ponce E. et al. Respiratory viruses and influenza-like illness: epidemiology and outcomes in children aged 6 months to 10 years in a multi-country population sample // J. Infect. 2017. Vol. 74, N 1. P. 29-41.

13. RuoholaA., Waris M., AllanderT.,ZieglerT., Heikkinen T., RuuskanenO. Viral etiology of common cold in children, Finland // Emerg. Infect. Dis. 2009. Vol. 15, N 2. P. 344-346.

14. Кокорева С.П., Трушкина А.В., Болышева Г.С., Михайлова И.С. Белявская А.Г. Этиологическая структура ОРВИ у детей в эпиАсезон 2014 2016 гг. // Инфекционные болезни. 2017. Т. 15, прил. 1. С. 133-134.

15. Асилова М.У., Мусабаев Э.И., Убайдумлаева Г.Б. Вирусные Аиареи в структуре острых кишечных инфекций у Аетей // Журнал инфекто могии. 2011. Т. 3, № 3. С. 56-59.

16. Епифанова Н.В., Новикова Н.А. Роль аденовирусов в возникновении острой кишечной инфекции у детей // МеАиА^ь. 2014. № 2. С. 45-57.

17. Зайцева А.Ю., Хмелевская И.Г., Калуцкий П.В. Кминико-иммуно^огические особенности течения вирусных диарей у Аетей // Вестник современной клинической медицины. 2017. Т. 10, № 2. С. 30-33.

18. Schnepf N., Resche-Rigon M., Chaillon A., Scemla A., Gras G., Semoun 0 . et al. High burden of non-influenza viruses in influenza-like illness in the early weeks of H1N1v epidemic in France // PLoS One. 2011 Vol. 6, N 8. Article ID e23514.

19. Савенкова М.С. Кишечный синаром при вирусных инфекциях у Аетей, перспективы мечения // Аетские инфекции. 2015. Т. 14, № 2 C. 45-51.

20. Головачева Е.Г., Афанасьева В.С., Осидак А.В., Афанасьева О.И. Образцова Е.В., Королева Е.Г. и Ар. Особенности Аинамики иммунного ответа при гриппе у детей на фоне интерферонотерапии // Аетские инфекции. 2017. Т. 16, № 1. С. 7-12.

21. Малова И.А., Баранова И.П. Роль метапневмовируса и бокавируса в развитии острых респираторных инфекций у госпитализированных больных в эпидсезоны 2011-2014 гг. в Пензенской области // Аетские инфекции. 2016. № 1. С. 59-63.

\section{REFERENCES}

1. Rubis L.V. Characteristics of the causative agents of acute respiratory viral infections and the importance of disinfection measures in preventing their spread. Detskie infektsii [Children's Infections]. 2018; 17 (1): 34-40. DOI: https://doi.org/10.22627/2072-8107-2018-17-1-34-40 (in Russian)

2. Chen N., et al. Epidemiological and clinical characteristics of 99 cases of 2019 novel coronavirus pneumonia in Wuhan, China: a descriptive study. Lancet. 2020; 395 (10 223): 507-13. DOI: https://doi.org/10.1016/ S0140-6736(20)30211-7

3. Kanner E.V., Maksimov M.L., Ermolaeva A.S., Gorelov A.V. Acute respiratory infections in children: features of the immune response and ways of correction. RMZH. Meditsinskoe obozrenie [RMJ. Medical Review]. 2018 8 (II): 74-8. (in Russian)

4. Zaytseva S.V. Rational therapy of acute respiratory infections in children. Pediatrics. Consilium Medicum. Pediatriya [Consilium Medicum. Pediatrics]. 2019; (4): 32-8. DOI: https://doi.org/10.26442/26586630.2 019.4.190748 (in Russian)

5. Gladkikh R.A., Molochny V.P., Butakova L.V., Trotsenko O.E., Reznik V.I., Polesko I.V. Clinical and etiological characteristics of acute respiratory viral infections in hospitalized children of the city of Khabarovsk in the epidemic seasons 2014-2017. Detskie infektsii [Children's Infections]. 2018 
17 (2): 6-14. DOI: https://doi.org/10.22627/2072-8107-2018-17-2-6-14 (in Russian)

6. Cebey-Lopez M., Herberg J., Pardo-Seco J., Gomez-Carballa A., Martinon-Torres N., Salas A., et al. Viral co-infections in pediatric patients hospitalized with lower tract acute respiratory infections. PLoS One. 2015 10 (9): e0136526. DOI: https://doi.org/10.1371/journal.pone.0136526 PMID:26332375

7. Allander T., Tammi M.T., Eriksson M., Bjerkner A., Tiveljung-Lindell A., Andersson B. Cloning of a human parvovirus by molecular screening of respiratory tract samples. Proc Natl Acad Sci USA. 2005; 102 (36): 12 891-6.

8. Ludvigsson J.F. Systematic review of COVID-19 in children show milder cases and a better prognosis than adults. Acta Paediatr. 2020; 109: 1088-95. DOl: https://doi.org/10.1111/apa.15270

9. Malakhov A.B., Rtischev A.Yu., Kolosova N.G. Influenza and upper respiratory tract infections in children: a strategy for choosing etiotropic therapy. Prakticheskaya pulmonologiya [Practical Pulmonology]. 2018; (2): 34-40. (in Russian)

10. Kokoreva S.P., Trushkina A.V., Razuvaev O.A., Kazartseva N.V. The etiological structure of acute respiratory diseases in the years 2009-2013 in children of Voronezh. Detskie infektsii [Children's Infections]. 2015; (4): 53-6. (in Russian)

11. Mikhaylova E.V., Chudakova T.K., Yarushkina M.S., Romanovskaya A.V., Khvorostukhina N.F. Respiratory syncytial virus infection: clinical and laboratory features. Detskie infektsii [Children's Infections]. 2017; 16 (2): 23-5. DOl: https://doi.org/10.22627/2072-8107-2017-16-223-25 (in Russian)

12. Taylor S., Lopez P., Weckx L., Borja-Tabora C., Ulloa-Gutierrez R. Lazcano-Ponce E., et al. Respiratory viruses and influenza-like illness: epidemiology and outcomes in children aged 6 months to 10 years in a multicountry population sample. J Infect. 2017; 74 (1): 29-41.

13. Ruohola A., Waris M., Allander T., Ziegler T., Heikkinen T., Ruuskanen 0 . Viral etiology of common cold in children, Finland. Emerg Infect Dis. 2009; 15 (2): 344-6.
14. Kokoreva S.P., Trushkina A.V., Bolysheva G.S., Mikhaylova I.S., Belyavskaya A.G. Etiological structure of ARVI in children in the 2014-2016 epidseason. Infektsionnye bolezni [Infectious Diseases]. 2017; 15 (suppl 1): 133-4. (in Russian)

15. Asilova M.U., Musabaev E.I., Ubaydullaeva G.B. Viral diarrhea in structure of acute intestinal infections in children. Zhurnal in fektologii [Journal of Infectology]. 2011; 3 (3): 56-9. DOl: https://doi. org/10.22625/2072-6732-2011-3-3-56-59 (in Russian)

16. Epifanova N.V., Novikova N.A. The role of adenoviruses in the occurrence of acute intestinal infection in children. MediAl'. 2014; (2): 45-57. (in Russian)

17. Zaytseva L.Yu., Khmelevskaya I.G., Kalutsky P.V. Clinical and immunological features of viral diarrhea in children. Vestnik sovremennoy klinicheskoy meditsiny [Bulletin of Contemporary Clinical Medicine]. 2017; 10 (2): 30-3. DOI: https://doi.org/10.20969/VSKM.2017.10(2).30-33 (in Russian)

18. Schnepf N., Resche-Rigon M., Chaillon A., Scemla A., Gras G., Semoun 0., et al. High burden of non-influenza viruses in influenza-like illness in the early weeks of H1N1v epidemic in France. PLoS One. 2011; 6 (8): e23514.

19. Savenkova M.S. Intestinal syndrome during viral infections in children, the prospects for treatment. Detskie infektsii [Children's Infections] 2015; 14 (2): 45-51. DOl: https://doi.org/10.22627/2072-8107-2015-142-15-24 (in Russian)

20. Golovacheva E.G., Afanas'eva V.S., Osidak L.V., Afanas'eva O.I., Obraztsova E.V., Koroleva E.G., et al. The dynamics of the immune responsem to influenza in children treated with interferon. Detskie infektsii [Children's Infections]. 2017; 16 (1): 7-12. DOI: https://doi.org/10.22627/2072 8107-2017-16-1-7-12 (in Russian)

21. Malova I.A., Baranova I.P. The Role of Bokavirus and Metapneumovirus in Development Acute Respiratory Infections in Hospitalized Patients in 2011-2014 years in Penza Region. Detskie infektsii [Children's Infections]. 2016; 15 (1): 59-63. DOI: https://doi.org/10.22627/2072-81072016-15-1-59-63 (in Russian) 